\title{
FACTORS OF UNCERTAINTY IN THE INTEGRATED MANAGEMENT OF WATER RESOURCES: THE CASE OF WATER REUSE
}

\author{
PABLO AZNAR-CRESPO ${ }^{1,2}$, ANTONIO ALEDO $^{1,2} \&$ JOAQUÍN MELGAREJO $^{1}$ \\ ${ }^{1}$ University Institute of Water and Environmental Sciences, University of Alicante, Spain. \\ ${ }^{2}$ Department of Sociology I, University of Alicante, Spain.
}

\begin{abstract}
The non-conventional water resources (water reuse (WR) and desalination) are a strategic option to compensate the structural water deficit of the southeast of Spain. In addition to increasing water availability and reducing the pressure on conventional resources, these resources show strategic functions at environmental, social and economic level. However, WR does not experience sufficient acceptance by some water users. Uncertainties regarding the quality of reclaimed water, food safety, price or regulations are factors of rejection or ambiguity. The results of a survey carried out on 114 users belonging to irrigation communities of several river basins in Spain are presented. In general, results show a moderate level of implementation of WR. However, the growth potential of WR is significantly high. This depends on water quality and price, which are the two most important valuation factors of WR. Regulations, food safety or water quality for crops generate uncertainty and concern among the irrigation communities. The effects on the environment or the control of availability are aspects positively valued. Conventional resources (transfers and groundwater) are better valued than non-conventional ones (WR and desalination). This constitutes a factor of vulnerability to consolidate the transformation of the Spanish hydrological model. The information presented can be useful to guide the design of future hydrological policies and reduce the socio-institutional vulnerability related to the integrated management of water resources.
\end{abstract}

Keywords: Irrigation Communities, Social Perception, Southeast of Spain. Uncertainty, Water Reuse.

\section{INTRODUCTION}

Water reuse (WR) is a strategic option to increase the supply of water resources in the deficit regions of Spain. The region of Murcia or the province of Alicante is exposed to a structural water deficit, caused by very little rainfall ( $<350 \mathrm{~mm} /$ year) and high evapotranspiration (high temperatures and insolation). In this sense, the effects of climate change are a threat to the southeast of Spain, where it is expected a reduction in rainfall of up to $30 \%$ and a considerable thermal increase in the medium-long term (CEDEX [1]). These climatic variations can favor a worsening of the drought episodes and force an unsustainable pressure on the water resources (Pascual et al. [2]; Valdes-Abellan et al. [3]). In this framework, non-conventional resources are important to optimize an integrated management and guarantee the continuity of the socio-economic development model of deficit regions (Olcina \& Mantero [4]; Morales et al. [5]). In Spain, the articulation of WR in water management began its expansion in 2004, with the repeal of the Ebro transfer project contemplated in the National Hydrological Plan of 2001. The modification of this plan caused a significant change in Spanish hydraulic policy, since it introduced management criteria more related to the WR and desalination than to the policy of transfers. At that time, the policy of transfers was exposed to socio-political tensions and important uncertainties regarding its environmental viability. The EU Water Framework Directive (Directive 2000/60/EC) also favored the transition of the Spanish hydrological model, directing management towards criteria such as environmental quality, sustainable use of water or technological development. 
Along with desalination, WR is the main alternative of this new paradigm of water resources management. This option increases the offer, reduces the pressure on conventional resources and shows socio-environmental advantages. At the environmental level, WR attenuates the overexploitation of aquifers and improves the ecological flow of rivers. It is a circular economy practice, which imitates the natural hydrological cycle of water in its phase of use and exploitation. This allows to stabilize the control of water availability, increasing the self-sufficiency of the territories (Garcia \& Pargament [6]). The cost of reclaimed water, in general, is affordable for users (Melgarejo [7]), especially when its consumption is subsidized by the public administration (Melgarejo \& López-Ortiz [8]). However, the growing demands on quality could impose the use of more advanced technologies that favor an increase in prices (Molina [9]).

Despite its advantages, WR has not yet obtained sufficient social acceptance, and currently faces some challenges that may compromise the generalization and consolidation of its practice. According to FAO [10], risk to public health is the main challenge facing WR. There is growing concern about chemical contaminants - known as 'emerging pollutants' (drugs, pesticides, hygiene products ...) - detected in reclaimed water, which come from the domestic and agricultural uses that the resource experiences throughout its lifecycle (Rosal et al. [11]). The effects of these pollutants on human health are not known exactly (Tejada et al. [12]), although effects of endocrine disruption have been proven (Patiño et al. [13]). Currently there are technologies capable of eliminating these substances (Deblonde et al. [14]), although their implementation could increase production costs and reduce the economic affordability of WR. Knowledge about the presence of emerging pollutants in reclaimed water can cause important changes in the regulations about treatment of reclaimed water, mainly because of the possibility that these substances are included in the quality parameters (Galvín [15]). Its control and regulation, despite offering public health guarantees, could require the reconversion of the current treatment systems. Another problem is the high conductivity that sometimes presents reclaimed water, especially in coastal areas (Yangali-Quintanilla et al. [16]). The excess of salinity causes some adverse effects in the crops, so that it is an important factor of concern among the irrigation communities (ICs). Finally, public opinion about the WR still does not reach optimal levels of satisfaction. March et al. [17], after studying the perception of citizenship in different municipalities of the province of Alicante (southeast of Spain), found an important concern about the energy and economic cost of the WR, as well as its impact on public health. WR faces significant challenges, which in essence could require the increase in the quality of reclaimed water and the maintenance of its economic affordability.

Knowledge about the social perception of WR is very limited (Melián-Navarro \& Fernández-Zamudio [18]). Although some researches in Spain have approached this subject (Domènech \& Saurí [19]; March et al. [17]; Costa [20]), the information about the different dimensions of WR is insufficient. WR is a new topic, in progressive growth, which requires exploratory initiatives that provide strategic information to guide future actions of integrated water management. The objective of this study is to describe the perception and implementation of WR by ICs in Spain. This group is the main socio-economic stakeholder directly linked to WR, so that knowledge about their concerns is strategic. To achieve this goal, a survey has been carried out to 114 users belonging to ICs. Multiple technical, social and economic aspects were asked. This research provides some notions about the way in which water users are adapting to the changes that the Spanish hydrological model is undergoing through the boom of non-conventional resources, the regressive dynamic of policy of transfers and the potential impacts of climate change. This study can offers key information about 
the socio-institutional vulnerability experienced by the system and its users in the face of new management realities and future hazards.

\section{MATERIAL AND METHODS}

\subsection{Case study}

The study population of this research is ICs of Spain. ICs are farmers' corporations created with the objective of managing the distribution of irrigation water among its members under agreed principles.

Due to the exploratory orientation of this study, the geographical dimension of the selected case studies (river basin) has not been subjected to statistical stratification criteria. However, those ICs that establish a direct relationship with WR have been more focused. These ICs belong to the river basins of southeastern Spain: Júcar and Segura. The case studies of these basins have a greater quantitative importance in the investigation. Figure 1 shows the percentage of study cases in the survey for each of the participating river basins. $59.6 \%$ of the cases belong to the two basins of the southeast. This high percentage is consistent with the WR level of this region. In Murcia and the Valencian Community $63 \%$ of the WR of Spain is carried out. The volume of WR in the rest of river basins is significantly lower, mainly because they have a lower water stress and/or a lower volume of irrigated area.

In relation to the socio-demographic characteristics of the sample, $64.9 \%$ were over 50 years old. $90.4 \%$ were men. $45.6 \%$ had university studies, $24.6 \%$ had secondary education, $16.7 \%$ had primary education and $13.2 \%$ had no studies. Finally, $37.7 \%$ of the respondents

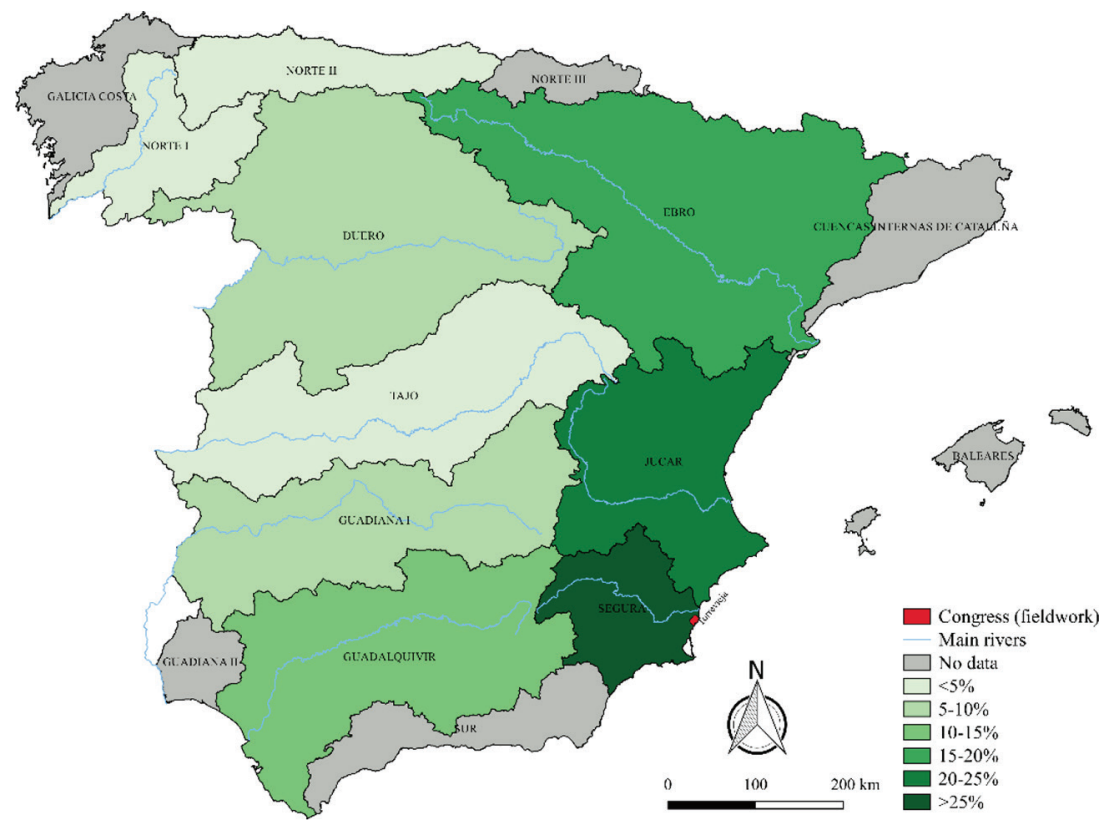

Figure 1: Percentage of sample by river basins.

Source: own elaboration. 
were irrigators (farmers), $31.6 \%$ managers of the ICs, $15 \%$ were administrative and $10.5 \%$ developed technical-scientific tasks in these corporations.

\subsection{Methodology}

The technique of data collection was the survey. This technique consisted in the formulation of structured questions through individual face-to-face interviews. In order to ensure the recruitment of a significant number of case studies belonging to the basins of Júcar and Segura, the fieldwork was carried out during 15 and 16 May 2018 at Torrevieja International Auditorium (Alicante), place where the XIV National Congress of Irrigation Communities was being held. The congress gathered 350 experts from agricultural sector, most of them belonging to ICs. During the fieldwork, 114 people were interviewed. This sample size was sufficient to satisfy the demands of a non-parametric exploratory study.

The nature of this research is descriptive-exploratory, since it proposes an approach to the most important general issues of WR in the field of irrigation. Several dimensions of this phenomenon are studied, so it has been difficult to deepen the study of sub-themes or specific issues. On the contrary, implementing a generalist approach has been advantageous due to the scarce information that exists in the specialized literature about WR perception.

\section{RESULTS}

In this section, the results of the research are presented, specifically the descriptive data of 19 analytical variables related to different aspects of WR. Three sub-sections or types of variables can be distinguished, which offer information about: implementation, perception and preferences.

\subsection{WR implementation}

According to the data (Table 1a), the percentage of users that implement WR is $50.9 \%$. Within this category, $44.2 \%$ stated that reclaimed water represents less than $30 \%$ of the total water resources managed to carry out the irrigation of crops (Table 1b). $38.5 \%$ indicated that reclaimed water accounts for between 30 and $50 \%$ of their water consumption. WR levels greater than $50 \%$ are residual among the interviewed cases.

On the other hand, the level of productive incidents related to WR implementation is low (Table 2a). 55\% of the cases said they suffer incidences with low frequency, while $28.3 \%$ indicated that they have never suffered any problems. The medium and high frequency of problems related to irrigation with reclaimed water represent residual categories.

Table 1: WR implementation levels.

\begin{tabular}{cccc}
\hline \multicolumn{2}{c}{ Water reuse (a) } & & \multicolumn{2}{c}{ Percentage of water reused (b) } \\
\hline Yes & $\mathbf{5 0 . 9 \%}$ & $<\mathbf{3 0 \%}$ & $\mathbf{4 4 . 2 \%}$ \\
No & $46.5 \%$ & $\mathbf{3 0 - 5 0 \%}$ & $38.5 \%$ \\
$\begin{array}{c}\text { DK/DA (do not know/do not } \\
\text { answer) }\end{array}$ & $2.6 \%$ & $\mathbf{5 0 - 7 0 \%}$ & $3.8 \%$ \\
- & - & $\mathbf{> 7 0 \%}$ & $5.8 \%$ \\
- & - & DK/DA & $3.5 \%$ \\
\hline
\end{tabular}


Table 2: Incidents during implementation and scope of affectation.

\begin{tabular}{|c|c|c|c|}
\hline \multicolumn{2}{|c|}{ Incident frequency (a) } & \multicolumn{2}{|l|}{ Scope of affectation (b) } \\
\hline Never & $28.3 \%$ & Crop toxicity & $4.5 \%$ \\
\hline Low frequency & $55.0 \%$ & Crop productivity & $9.1 \%$ \\
\hline Medium frequency & $6.7 \%$ & Soil contamination & $11.4 \%$ \\
\hline High frequency & $1.7 \%$ & Contamination of other types of water & $13.6 \%$ \\
\hline DK/DA & $8.3 \%$ & Pumping and storage & $38.6 \%$ \\
\hline- & - & DK/DA & $22.7 \%$ \\
\hline
\end{tabular}

When problems occur (Table 2b), these usually affect WR infrastructures (pumping and storage of reclaimed water). Irrigators (farmers) are likely to point to infrastructure problems as a way to show concerns about the energy cost of transporting reclaimed water. On the other hand, a considerable percentage of respondents declared not knowing the incidents they suffer. The contamination of other types of water (water transferred or rainwater), despite not being a majority, occurs in $13.6 \%$ of cases. The rest of the categories do not present significant response percentages.

\subsection{WR assessment}

On the one hand, the economic cost of WR seems to be a matter of great ambiguity. $40.4 \%$ of respondents said they do not know the price of reclaimed water (Table 3a). Most people who proposed a quantity chose the categories below $0.40 € / \mathrm{m}^{3}$. A very low percentage of people indicated prices higher than $0.40 € / \mathrm{m}^{3}$. However, the highlight of this variable is the significant ignorance of the price of reclaimed water.

In relation to the price assessment (Table $3 b$ ), the highest percentage of responses is in the category 'DK/DA', which is consistent with the high level of ignorance that appears in the data of the previous variable. However, a quarter of the respondents considered that the price of reclaimed water is 'regular'. The lowest percentages are at the extremes ('very good' and 'very bad'). When converting the ordinal levels of the question into numerical scale positions ( 1 as very bad; 2 as bad; 3 as regular; 4 as good; and 5 as very good), the average score of the price assessment is 2.96 out of 5 .

Table 3: Perception and assessment of WR price.

\begin{tabular}{cccc}
\hline \multicolumn{2}{c}{ Price perception (a) } & \multicolumn{2}{c}{ Price (b) } \\
\hline$<\mathbf{0 . 1 0} € \mathbf{~ m}^{\mathbf{3}}$ & $13.2 \%$ & Very bad & $4.4 \%$ \\
$\mathbf{0 . 1 0}-\mathbf{0 . 2 0} € \mathbf{~ m}^{\mathbf{3}}$ & $11.4 \%$ & Bad & $18.4 \%$ \\
$\mathbf{0 . 2 0}-\mathbf{0 . 3 0} € \mathbf{~ m}^{\mathbf{3}}$ & $13.2 \%$ & Regular & $26.3 \%$ \\
$\mathbf{0 . 3 0 - 0 . 4 0} € \mathbf{~ m}^{\mathbf{3}}$ & $14.0 \%$ & Good & $15.8 \%$ \\
$\mathbf{0 . 4 0 - 0 . 5 0} € \mathbf{~ m}^{\mathbf{3}}$ & $4.4 \%$ & Very good & $4.4 \%$ \\
$>\mathbf{0 . 5 0} € \mathbf{~ m}^{\mathbf{3}}$ & $3.5 \%$ & DK/DA & $\mathbf{2 8 . 9 \%}$ \\
$\mathbf{D K} / \mathbf{D A}$ & $\mathbf{4 0 . 4 \%}$ & - & - \\
\hline
\end{tabular}


Table 4: Assessment of environmental effects and quality for crops of WR.

\begin{tabular}{cccc}
\hline \multicolumn{2}{c}{ Environmental effects (a) } & \multicolumn{2}{c}{ Quality for crops (b) } \\
\hline Very bad & $5.3 \%$ & Very bad & $6.1 \%$ \\
Bad & $10.5 \%$ & Bad & $19.3 \%$ \\
Regular & $\mathbf{3 0 . 7 \%}$ & Regular & $\mathbf{2 6 . 3 \%}$ \\
Good & $25.4 \%$ & Good & $19.3 \%$ \\
Very good & $17.5 \%$ & Very good & $16.7 \%$ \\
DK/DA & $8.8 \%$ & DK/DA & $11.4 \%$ \\
\hline
\end{tabular}

In relation to the effects on the environment (Table 4a), the most repeated category is 'regular'. However, the percentage of responses is significantly higher in the positive categories than in the negative ones. Therefore, the average of this variable is 3.44 out of 5. Opinion about this topic is generally positive, and this may be due to ability of WR to control wastewater discharges or to carry out practices such as artificial recharge of aquifers.

On the other hand, the general assessment of the quality of reclaimed water for crops is again 'regular' (Table 4b), with $26.3 \%$ of survey replies placed in this category. However, the number of responses located in the negative range is greater than in the previous variable. Therefore, the average score of this variable is 3.24 out of 5 .

The food safety of reclaimed water for irrigation is a subject valued negatively by the respondents (Table 5a). 31.6\% think that WR presents a 'regular' food security. It also highlights the category 'bad', which accounts for $24.6 \%$ of the responses. The average of this variable is 2.99 out of 5 , the second lowest of this block of variables. The quality and food safety of the crops seems to be a matter of central concern among the irrigators, which could be related to the knowledge about the presence of emerging pollutants in reclaimed water.

Regarding the control of resource availability (Table $5 \mathrm{~b}$ ), the assessment is relatively positive. The most repeated category is 'good', with $27.2 \%$ of survey replies. The category 'very good' concentrates $19.3 \%$ of the opinions of the respondents, which also happens with the category 'regular'. The average score of this variable is 3.44 out of 5. In general, the availability of the resource is valued positively. By depending on the supply flows (urban and agricultural), its control arouses less uncertainty than conventional resources (rainwater, aquifers, water transferred...).

Table 5: Assessment of food safety and control of availability of WR.

\begin{tabular}{cccc}
\hline \multicolumn{2}{c}{ Food safety (a) } & \multicolumn{2}{c}{ Control of availability (b) } \\
\hline Very bad & $7.0 \%$ & Very bad & $7.9 \%$ \\
Bad & $24.6 \%$ & Bad & $12.3 \%$ \\
Regular & $\mathbf{3 1 . 6 \%}$ & Regular & $19.3 \%$ \\
Good & $14.9 \%$ & Good & $\mathbf{2 7 . 2 \%}$ \\
Very good & $11.4 \%$ & Very good & $19.3 \%$ \\
DK/DA & $9.6 \%$ & DK/DA & $9.6 \%$ \\
\hline
\end{tabular}


Table 6: Assessment of regulations and infrastructures of WR.

\begin{tabular}{cccc}
\hline \multicolumn{2}{c}{ Regulations (a) } & \multicolumn{2}{c}{ Infrastructures (b) } \\
\hline Very bad & $2.6 \%$ & Very bad & $14.0 \%$ \\
Bad & $21.9 \%$ & Bad & $18.4 \%$ \\
Regular & $\mathbf{3 1 . 6 \%}$ & Regular & $\mathbf{2 8 . 1 \%}$ \\
Good & $21.1 \%$ & Good & $16.7 \%$ \\
Very good & $3.5 \%$ & Very good & $6.1 \%$ \\
DK/DA & $17.5 \%$ & DK/DA & $15.8 \%$ \\
\hline
\end{tabular}

In relation to regulations (Table 6a), its assessment is 'regular', since its average score is 3.01 out of 5 . This category concentrates $31.6 \%$ of the survey replies. The category 'bad' also stands out, since it contains $21.9 \%$ of the total opinions of the people surveyed. However, the high percentage of responses that agglutinates the category 'DK/DA' is surprising. As with pricing, regulations are an important issue of ambiguity, perhaps related to the possibility of developing new regulatory frameworks in the immediate future.

However, the most valued issue in this block is the infrastructures used to implement WR (Table 6b). Despite the most repeated category is 'regular', the weight of the categories 'bad' and 'very bad' stands out, since both make up $32.4 \%$ of the opinions. This explains why the average score of this variable is 2.79 out of 5 , the lowest in this block of variables. The problems related to the costs of implementation (infrastructures) the reclaimed water (identified in section 3.1), could explain this negative assessment.

\subsection{WR preferences}

To identify the preferences about the different water supply options, data on the valuation of each of them are presented. Regarding non-conventional options, desalination is valued negatively, and is the worst rated of the four supply sources analyzed (Table 7a). Although the most repeated category is 'regular' with $27.2 \%$, the 'very bad' option stands out considerably, since it concentrates a quarter of the answers. The average score obtained is 2.78 out of 5 . The overall rating is negative, and this may be related to problems such as the cost of desalinated water or the damage caused to crops by their concentrations of chlorine, sodium or boron.

Table 7: Assessment of non-conventional resources.

\begin{tabular}{cccc}
\hline \multicolumn{2}{c}{ Desalination (a) } & \multicolumn{2}{c}{ Water reuse (b) } \\
\hline Very bad & $25.4 \%$ & Very bad & $4.4 \%$ \\
Bad & $10.5 \%$ & Bad & $14.0 \%$ \\
Regular & $\mathbf{2 7 . 2 \%}$ & Regular & $21.9 \%$ \\
Good & $24.6 \%$ & Good & $\mathbf{3 3 . 3 \%}$ \\
Very good & $7.9 \%$ & Very good & $26.3 \%$ \\
DK/DA & $4.4 \%$ & DK/DA & - \\
\hline
\end{tabular}


Table 8: Assessment of conventional resources.

\begin{tabular}{cccc}
\hline \multicolumn{2}{c}{ Groundwater (a) } & \multicolumn{2}{c}{ Transfers (b) } \\
\hline Very bad & - & Very bad & $5.3 \%$ \\
Bad & $17.5 \%$ & Bad & $8.8 \%$ \\
Regular & $\mathbf{3 7 . 7 \%}$ & Regular & $14.0 \%$ \\
Good & $28.9 \%$ & Good & $27.2 \%$ \\
Very good & $14.0 \%$ & Very good & $\mathbf{4 1 . 2 \%}$ \\
DK/DA & $1.8 \%$ & DK/DA & $3.5 \%$ \\
\hline
\end{tabular}

As for WR (Table 7b), the most repeated category is 'good', with 33.3\% of the answers. The percentage of responses of the category 'very good' is also important, since one in four case studies chose this option. WR is the second best analyzed option, with an average score of 3.63 out of 5. It is a positive overall rating, which positions WR as the non-conventional option best valued by irrigators. However, reclaimed water is also exposed to some drawbacks, such as high levels of conductivity or high concentrations of phytotoxic ions. The average score of the non-conventional options (desalination and WR) is 3.21 out of 5 .

As for conventional options, groundwater has an average score of 3.40 out of 5 (Table 8a). The most repeated category is 'regular', although the option 'good' also stands out. The assessment is relatively positive, although with some nuances, which appear around the high percentage of opinions concentrated in the category 'bad'. Despite being a conventional option, groundwater also presents some drawbacks. Problems such as pollution or partial control of the availability of the resource prevent irrigators from experiencing greater satisfaction with this resource.

The favorite option for the irrigators consulted is the water transferred (Table 8b). His score is the highest of the four options consulted, with an average of 3.94 out of 5. The most repeated category is 'very good', with $41.2 \%$ of the answers. The second most repeated category is 'good', which concentrates $27.2 \%$ of the opinions expressed. The lower price of the transferred water and its higher degree of quality are factors that can explain this overall positive assessment. The average score of conventional options (groundwater and transferred water) is 3.67 out of 5, almost half a point more than the average of non-conventional options (desalination and WR). Approximately, this data may reflect the preference of the conventional hydrological model by irrigators, especially those belonging to the deficit river basins of southeastern Spain.

On the other hand, it is interesting to analyze how price and quality influence the assessment and implementation of WR in irrigation. There is a very significant difference between those who declared reusing at the moment and those who expressed their intention to reuse if the prices were more competitive and the quality reached an optimum level. With these conditions, $80.7 \%$ of users would implement WR (Table 9a), which represents a potential increase of $34.2 \%$ users.

Under these assumptions (better price and quality), the percentage of water reclaimed over the total of water resources consumed would also increase considerably (Table 9b). The option ' $>70 \%$ ' becomes the most repeated category. However, the option ' $<30 \%$ ' remains the second most numerous category. 
Table 9: Level of implementation of WR with optimum quality and competitive price $(*)$.

\begin{tabular}{cccc}
\hline \multicolumn{2}{c}{ Water reuse* (a) $^{2}$} & \multicolumn{2}{c}{ Percentage of water reused* (b) } \\
\hline Yes & $\mathbf{8 0 . 7 \%}$ & $<\mathbf{3 0 \%}$ & $21.1 \%$ \\
No & $19.3 \%$ & $\mathbf{3 0 - 5 0 \%}$ & $16.7 \%$ \\
DK/DA & - & $\mathbf{5 0 - 7 0 \%}$ & $17.5 \%$ \\
- & - & $>\mathbf{7 0 \%}$ & $\mathbf{2 5 . 4 \%}$ \\
- & - & DK/DA & $19.3 \%$ \\
\hline
\end{tabular}

Table 10: Willingness to pay more for a reclaimed water with optimum quality level.

\begin{tabular}{cc}
\hline \multicolumn{2}{c}{ Willingness to pay more (a) } \\
\hline No & $29.8 \%$ \\
Yes, with a minimum price increase & $\mathbf{3 5 . 1 \%}$ \\
Yes, with a moderate price increase & $24.6 \%$ \\
Yes, even if the price increase is high & $1.8 \%$ \\
DK/DA & $8.8 \%$ \\
\hline
\end{tabular}

Finally, to continue to test the influence of costs, the willingness to pay a higher price for water with an optimum quality was analyzed (Table 10). $35.1 \%$ of respondents said they were willing to pay a higher price as long as the increase was minimal. This option constitutes the most repeated category. Secondly, $29.8 \%$ of the users declared that they were not willing to pay more for reclaimed water with higher quality. One in four people showed their willingness to assume a moderate price increase. Only $1.8 \%$ of the respondents were in favor of facing a high price increase. This shows the enormous importance of the price of water in the assessment of different water sources by irrigators.

\section{CONCLUSIONS}

The results allow the interpretation of four types of uncertainty related to the perception and implementation of WR, as well as the way in which the ICs -water users in general- are adapting to the changes experienced by the Spanish hydrological model. In the first place, an economic uncertainty can be appreciated. The price and costs of WR are a primary vector in the valuation of this water supply. In parallel are the quality levels, which also influence the opinion that water users have about WR. However, it is highly probable that the increase in quality of the reclaimed water has to be accompanied by an increase in treatment costs, which consequently could reduce the affordability of the prices.

On the other hand, a technological uncertainty can be distinguished. The quality determines the value granted to water supply options. The perception of respondents about the food safety of reclaimed water confirms this idea. The emerging pollutants constitute a fundamental factor of uncertainty, since their regulation could require the conversion of current treatment systems and the hardening of quality parameters. These changes, which could force the adaptation of some users and management mechanisms, could hinder the technological transition of the water management model. 
Third, a socio-political uncertainty can be perceived. Users feel less adherence to the new water management model (non-conventional resources), as they continue to show preference for elements of the conventional hydraulic paradigm. The widespread support for transfers especially in the deficit river basins of the southeast- confirms this idea. This constitutes a significant factor of uncertainty, since the new management frameworks are increasingly oriented towards the development of non-conventional water supply practices. In turn, climate change could alter the hydrological regime of the basins of northern Spain and increase the socio-political conflict in the decision-making of transfer projects currently implemented.

Finally, a cultural uncertainty can be estimated. This is related to the influence of the habits acquired by water users on their willingness to accept the changes experienced by the sector in the short, medium and long term. The partial validity of the conventional hydraulic model -progressively oriented towards exceptionality- and the support received by users are factors that could hinder the internalization of the changes faced by the management system. The hydrological culture, if it does not experience an adaptation, could be overcome by the impacts of climate change, since this hazard could have a dimension not yet contemplated in the field of water resources.

\section{ACKNOWLEDGEMENTS}

This study has been conducted within the grant received from the Programa Nacional de Formación de Profesorado Universitario (FPU) conceded by the Spanish Ministry of Science to the first author. The authors also acknowledge the support provided by the project LIFE15 ENV/ES/000598 'Development of an efficient and sustainable methodology for emerging pollutants removal in WWTPs (EMPORE)' funded by the European Commission (EU).

\section{REFERENCES}

[1] CEDEX, Evaluación del impacto del cambio climático en los recursos hídricos y sequías en España. Informe técnico. Centro de Estudios Hidrográficos, 2017.

[2] Pascual, D., Plà, E., López-Bustins, J.A., Retana, J. \& Terradas, J., Impacts of climate change on water resources in the Mediterranean Basin: A case study in Catalonia, Spain. Hydrological Sciences Journal, 60(12), pp. 2132-2147, 2015. https://doi.org/10 $.1080 / 02626667.2014 .947290$

[3] Valdes-Abellan, J., Pardo, M.A. \& Tenza-Abril, A.J., Observed precipitation trend changes in the western Mediterranean region. International Journal of Climatology, 37(1), pp. 1285-1296, 2017. https://doi.org/10.1002/joc.4984

[4] Cantos, J.O. \& Mantero, E.M., Recursos de agua no convencionales en España: Estado de la cuestión. Investigaciones Geográficas, 51, pp. 131-163, 2010. https://doi. org/10.14198/INGEO2010.51.06

[5] Morales, A.P., Meseguer, E.G. \& Espín, J.M.G., Las aguas residuales regeneradas como recurso para los regadíos de la Demarcación Hidrográfica del Segura (España). Boletín de la Asociación de Geógrafos Españoles, 64, pp. 151-175, 2014. http://dx.doi. org/10.21138/bage.1691

[6] Garcia, X. \& Pargament, D., Reusing wastewater to cope with water scarcity: Economic, social and environmental considerations for decision-making. Resources, Conservation and Recycling, 101, pp. 154-166, 2015. https://doi.org/10.1016/j.resconrec.2015.05.015

[7] Melgarejo, J., Efectos ambientales y económicos de la reutilización del agua en España. Clm. Economía, 15, pp. 245-270, 2009. 
[8] Melgarejo, J. \& López-Ortiz, M.I., Depuración y reutilización de aguas en España. Agua y territorio, 8, pp. 22-35, 2016. https://dx.doi.org/10.17561/at.v0i8.3293

[9] Molina, A., Aproximación al régimen jurídico de la reutilización de aguas regeneradas en España. Agua y territorio, 8, pp. 36-47, 2016. https://dx.doi.org/10.17561/ at.v0i8.3294

[10] FAO, Reutilización del agua en la agricultura: ¿Beneficios para todos? Informe sobre temas hídricos. Organización de las Naciones Unidas para la Alimentación y la Agricultura, Roma, 2013.

[11] Rosal, R., Rodríguez, A., Perdigón-Melón, J.A., Petre, A., García-Calvo, E., Gómez, M.J. \& Fernández-Alba, A.R., Occurrence of emerging pollutants in urban wastewater and their removal through biological treatment followed by ozonation. Water research, 44(2), pp. 578-588, 2010. https://doi.org/10.1016/j.watres.2009.07.004

[12] Tejada, C., Quiñonez, E. \& Peña, M., Contaminantes emergentes en aguas: metabolitos de fármacos: una revisión. Revista Facultad de Ciencias Básicas, 10(1), pp. 80-101, 2014. https://doi.org/10.18359/rfcb.341

[13] Patiño, Y., Díaz, E. \& García, S.O., Microcontaminantes emergentes en aguas: tipos y sistemas de tratamiento. Avances en Ciencias e Ingeniería, 5(2), pp. 1-20, 2014.

[14] Deblonde, T., Cossu-Leguille, C. \& Hartemann, P., Emerging pollutants in wastewater: a review of the literature. International Journal of Hygiene and Environmental Health, 214(6), pp. 442-448, 2011. https://doi.org/10.1016/j.ijheh.2011.08.002

[15] Galvín, R.M, Control de calidad en las aguas residuales y regeneradas: parámetros a controlar en función de las normativas aplicables y nuevas tendencias. Tecnoaqua, 5, pp. 50-63, 2014.

[16] Yangali-Quintanilla, V., Li, Z., Valladares, R., Li, Q. \& Amy, G., Indirect desalination of Red Sea water with forward osmosis and low pressure reverse osmosis for water reuse. Desalination, 280(1-3), pp. 160-166, 2011. https://doi.org/10.1016/j.desal.2011.06.066

[17] March, H., Hernández, M. \& Saurí, D., Percepción de recursos convencionales y no convencionales en áreas sujetas a estrés hídrico: el caso de Alicante. Revista de Geografía Norte Grande, 60, pp. 153-172, 2015. http://dx.doi.org/10.4067/S071834022015000100009

[18] Melián-Navarro, A. \& Fernández-Zamudio, M.A., Reutilización de agua para la agricultura y el medioambiente. Agua y territorio, 8, pp. 80-92, 2016. https://dx.doi. org/10.17561/at.v0i8.3298

[19] Domènech, L. \& Saurí, D., Socio-technical transitions in water scarcity contexts: Public acceptance of greywater reuse technologies in the Metropolitan Area of Barcelona. Resources, Conservation and Recycling, 55(1), pp. 53-62, 2015. https://doi.org/10.1016/j. resconrec.2010.07.001

[20] Costa, D. A., Estudio de gestión hídrica en la Comarca de la Vega Baja del Segura. Especial incidencia en el uso agrario del agua [Doctoral Thesis]. Universidad Miguel Hernández, Elche, 2015. 